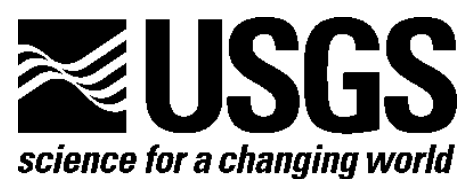

\title{
MODIS Phenology Image Service ArcMap Toolbox
}

By Colin Talbert, Tim Kern, Jeff Morisette, Don Brown, and Kevin James

Prepared in cooperation with the National Park Service and the Great Northern Landscape Conservation Cooperative

Open-File Report 2013-1250

U.S. Department of the Interior

U.S. Geological Survey 


\section{U.S. Department of the Interior \\ SALLY JEWEL, Secretary}

\section{U.S. Geological Survey \\ Suzette M. Kimball, Acting Director}

U.S. Geological Survey, Reston, Virginia: 2013

For more information on the USGS-the Federal source for science about the Earth, its natural and living resources, natural hazards, and the environment-visit http://www.usgs.gov or call 1-888-ASK-USGS

For an overview of USGS information products, including maps, imagery, and publications, visit $h$ ttp://www.usgs.gov/pubprod

To order this and other USGS information products, visit $h$ ttp://store.usgs.gov

Suggested citation:

Talbert, Colin; Kern, Tim; Morisette, Jeff; Brown, Don; and James, Kevin, 2013, MODIS phenology image service ArcMap toolbox: U.S. Geological Survey Open-File Report 2013-1250, 6 p., http://pubs.usgs.gov/of/2013/1250/.

Any use of trade, firm, or product names is for descriptive purposes only and does not imply endorsement by the U.S. Government.

Although this program has been used by the U.S. Geological Survey (USGS), no warranty, expressed or implied, is made by the USGS or the U.S. Government as to the accuracy and functioning of the program and related program material nor shall the fact of distribution constitute any such warranty, and no responsibility is assumed by the USGS in connection therewith.

Although this information product, for the most part, is in the public domain, it also contains copyrighted materials as noted in the text. Permission to reproduce copyrighted items must be secured from the copyright owner. 


\section{Contents}

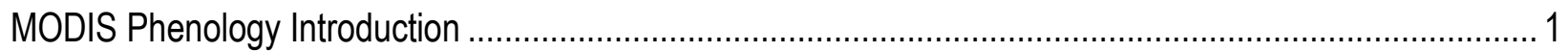

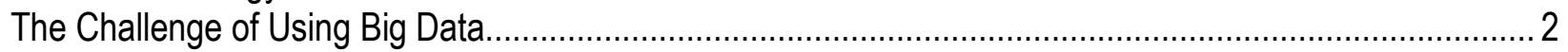

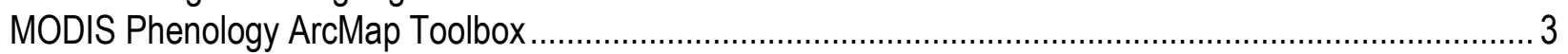

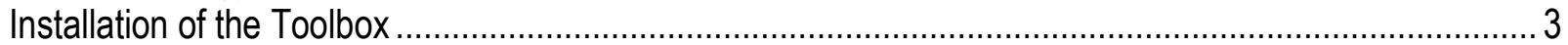

Using the "Add Phenology Layer to Display" Tool....................................................................... 5

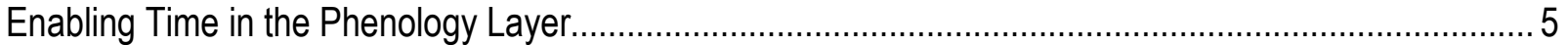

Using the "Download Local Files" Tool........................................................................................ 5

Using the "Summarize Phenology Data for Polygons" Tool .............................................................. 6

Notes for Using This Toolset and the Image Services ………........................................................ 6

\section{Figures}

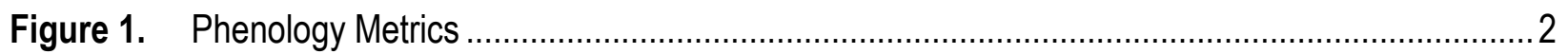

Figure 2. How to add the MODIS phenology toolbox to ArcMap....................................................

Figure 3. The Phenology Tools toolbox added to ArcToolbox in ArcMap .......................................... 4

Figure 4. Opening the Time Slider toolbar. ……………......................................................... 5

Figure 5. Cycling through multiple years' worth of data with the Time Slider toolbar. ............................. 5 


\title{
MODIS Phenology Image Service ArcMap Toolbox
}

\author{
By Colin Talbert1, Tim Kern¹, Jeff Morisette'1, Don Brown², and Kevin James ${ }^{3}$
}

\section{MODIS Phenology Introduction}

Seasonal change is important to consider when managing conservation areas at landscape scales. The study of such patterns throughout the year is referred to as phenology. Recurring lifecycle events that are initiated and driven by environmental factors include animal migration and plant flowering. Phenological events capture public attention, such as fall color change in deciduous forests, the first flowering in spring, and for those with allergies, the start of the pollen season. These events can affect our daily lives, provide clues to help understand and manage ecosystems, and provide evidence of how climate variability can affect the natural cycle of plants and animals. Phenological observations can be gathered at a range of scales, from plots smaller than an acre to landscapes of hundreds to thousands of acres. Linking these observations to diverse disciplines such as evolutionary biology or climate sciences can help further research in species and ecosystem responses to climate change scenarios at appropriate scales.

A cooperative study between the National Park Service (NPS), the U.S. Geological Survey (USGS), and the National Aeronautics and Space Administration (NASA) has been exploring how satellite information can be used to summarize phenological patterns observed at the park or landscape scale and how those summaries can be presented to both park managers and visitors. This study specifically addressed seasonal changes in plants, including the onset of growth, photosynthesis in the spring, and the senescence of deciduous vegetation in the fall. The primary objective of the work is to demonstrate that seasonality even in protected areas changes considerably across years. A major challenge is to decouple natural variability from possible trends - directional change that can lead to a permanent and radically different ecosystem state. Trends can be either a gradual degradation of the landscape (often from external influences) or steady improvement (by implementing long-term conservation plans). In either case, it is important to first grasp the magnitude of natural variation so that it is not confused with actual trends.

This work used existing and freely available remote sensing data, specifically the NASAfunded 250-meter (m) spatial resolution land-surface phenology product for North America. This product is calculated from an annual record of vegetation health observed by NASA's Moderate Resolution Imaging Spectroradiometer (MODIS) instrument. The land-surface phenology product is, in essence, a method to summarize all the observations throughout a year into a few key, ecologically relevant "metrics" (see fig. 1).

\footnotetext{
${ }^{1}$ U.S. Geological Survey

${ }^{2}$ Contractor to U.S. Geological Survey

${ }^{3}$ National Park Service
} 


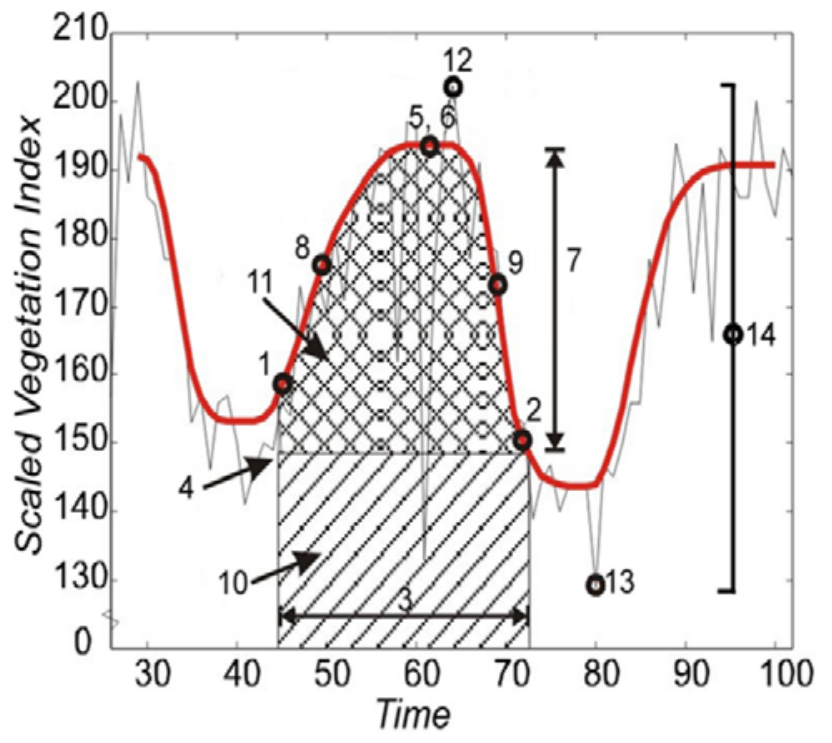

1. greenups

2. browndowns

3. season lengths

4. base levels

5. peak dates

6. max peak values

7. amplitudes

8. greenup rates

9. browndown rates

10. large integrals

11. small integrals

12. annual maximum value

13. annual minimum value

14. annual mean value

Figure 1. Phenology metrics.

Even though NASA is producing the MODIS phenology product for all of North America, the phenology metrics must be processed into files ready for geographic information systems (GIS) or summarized graphically to be made easily accessible to park managers or incorporated into interpretative material. Through current arrangements, data and graphics from the year 2000 onward for several pilot parks within the Great Plains are being prepared by the USGS Fort Collins Science Center. Discussion is underway to formalize cooperative efforts between the NASA Goddard Space Flight Center, the USGS Fort Collins Science Center, and the NPS Inventory and Monitoring (I\&M) Division.

Inventory and monitoring network ecologists and park natural resource managers interested in linking phenology and climate at network or park scales will be able to access these remote sensing phenology products through links on the NPScape program Web site. Specialists can associate these GIS data products with existing datasets to analyze seasonal changes at multiple spatial and temporal scales. Resource managers can use the composite phenology graphics to characterize changes in growing season. Park interpretive staff can use land-surface phenology maps in public discussions of seasonal changes in plant communities. These products and the associated methods from this project will be preserved and related to other landscape metrics through NPScape. Base products available for parks and surrounding landscapes include source and processed data, associated metadata, a standard operating procedure for land-surface phenology consistent with I\&M protocols, and data visualization tools for parks and networks to efficiently generate new customized products (in development).

\section{The Challenge of Using Big Data}

Many research and management questions require the use of datasets that are difficult for the average analyst or manager to use. Some of the impediments include large data sizes, file formats such as $\mathrm{HDF}$ and netCDF ${ }^{4}$ that require conversion for a particular application, tiled data that require subsetting or mosaicking before use, or tricky preprocessing such as re-projection,

\footnotetext{
${ }^{4} \mathrm{HDF}$, hierarchical data format; netCDF, network common data form
} 
rescaling, or correctly handling no-data values. While expert users are familiar with and equipped to handle these challenges, many other potential users do not have the resources to utilize the data. Because data can now be delivered as a service and consumed by a user-friendly client application, it is possible to mitigate some of these hurdles.

The MODIS phenology data delivered here provide a good example of these challenges. In its native format, the data are delivered in a series of individual 10-degree tiled HDF files based on the MODIS 250-m land grid (http://modis-land.gsfc.nasa.gov/MODLAND_grid.html). Understanding the file naming convention requires research into how MODIS data are delivered.

In order to use the data in an ArcGIS analysis, one must first identify the tiles of interest then convert them to a more standard file format, re-project them using a custom defined coordinate transformation, and mosaic the resulting outputs into a single file for further analysis. For all but the most trivial of tasks, the above workflow can only be accomplished by writing custom geoprocessing scripts. Complete FGDC ${ }^{5}$ metadata for the source data are distributed with the toolbox in the "... DoclMetadata" folder.

Our goal is to take a dataset that currently requires specialized expertise and a substantial time investment and deliver it seamlessly to managers and analysts. Also, by providing an ArcMap client toolbox, we can deliver information about the dataset, best uses for the data, and tools designed to inform management decisions directly. By having a single expert do the necessary and time-consuming pre-processing ahead of time, the overhead for analysis is dramatically reduced. This increase in efficiency should translate into increased use of the delivered data and accelerated derivative research.

\section{MODIS Phenology ArcMap Toolbox}

The suite of tools we have produced is delivered as a toolbox written for ArcMap version 10.0. The tools are written in Python, a programming language used by many GIS analysts. The functionality does require the commercial ESRI ArcGIS package, but this package is very commonly used and is available to most GIS analysts and managers. While the tools do not require strong GIS skills, a basic understanding of GIS concepts and the ArcGIS software is helpful.

Three tools are currently distributed in the toolbox. The first is a tool that allows a user to bring a layer of the phenology data directly into an open ArcMap document. This tool would be used for data exploration, cartographic purposes, and for general use in geoprocessing. The second tool allows a user to select subsets of the data and save the services as local geospatial files. This tool would be used by analysts requiring the data in applications that are not set up to handle ESRI Image Service consumption, for example Maxent or R. The third tool provides analysis and statistics of the data for a single polygon or set of polygons of interest. This tool would be used by managers to view the phenological response for individual management units or study sites.

\section{Installation of the Toolbox}

The suite of tools is available from USGS ScienceBase for download at https://my.usgs.gov/catalog/PhenoImageServer. The tool is delivered as a zipped folder containing a toolbox, a series of Python scripts, associated layer files, documentation, and an R script. The zipped folder should be downloaded from ScienceBase and unzipped into a known

\footnotetext{
${ }^{5}$ Federal Geographic Data Committee
} 
location. The toolbox can then be added to ArcMap by right-clicking the root of your ArcToolbox tree, selecting "Add Toolbox..." (fig. 2), and navigating to the file "Phenology Tools.tbx" at the root of the unzipped folder.

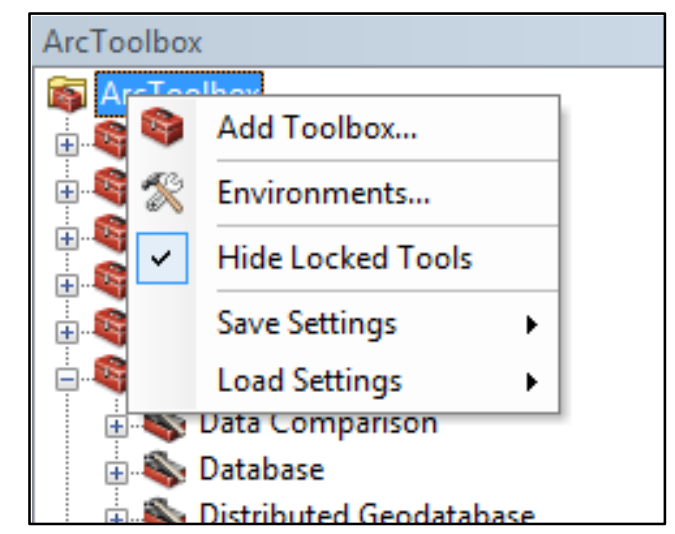

Figure 2. How to add the MODIS phenology toolbox to ArcMap.

Once added, the toolbox will appear in the list of available toolboxes (fig. 3).

\begin{tabular}{|l|l|}
\hline Parcel Fabric Tools \\
Phenology Tools \\
- Add Phenology Layer to Display \\
Download Local Files \\
Schematics Tools \\
Server Tools \\
\hline
\end{tabular}

Figure 3. The Phenology Tools toolbox added to ArcToolbox in ArcMap.

The tools can then be launched by double-clicking the tool name.

The first two data analysis tools require no additional software. The "Summarize Phenology data for polygon" tool, however, requires the R statistical software to create graphics. The R software can be obtained for free from http://www.r-project.org. This tool was tested against $\mathrm{R}$ version 2.14 , but it will likely work with older versions. The polygon tool can still be used if $\mathrm{R}$ is not installed, but no graphic will be produced. The tool will produce a $\mathrm{CSV}^{6}$ file of extracted values that can be analyzed or visualized in other software packages.

Detailed information about what each tool does and the purpose of each parameter is displayed in a help panel on the right side of the opened tool form. The user should resize the form or click the "Show Help>>" button if the panel is not visible. The panel will update to show information on each tool as it is opened. The panel also includes hyperlinks to supporting documents; shift-clicking will open a document in a new window.

\footnotetext{
${ }^{6} \mathrm{CSV}$, comma-separated values
} 


\section{Using the "Add Phenology Layer to Display" Tool}

The "Add Phenology Layer to Display" tool brings a layer of the phenology data directly into the current ArcMap document and can be used for data exploration, cartographic purposes, and for general use in geoprocessing. The layer added is displayed with relevant symbology already set. Because the data displayed are delivered as an ESRI Image service, the current extent of the map will not matter-one should be able to pan and zoom the data seamlessly. Also, because most of the geoprocessing tools that require raster inputs in ArcToolbox have been designed to recognize ESRI Image services, the resulting layer can be dragged into the input parameter boxes for other tools and used as if it were a local resource.

\section{Enabling Time in the Phenology Layer}

When adding a layer, selecting the default value "All" for the year parameter will activate the option to use the built-in time slider functionality in ArcMap. To use this feature, the user should right-click on the layer name to bring up the layer properties dialog, select the "Time" tab on the far right, and check the box next to "Enable time on this layer." After closing the dialog, the user can open the "Time Slider" toolbar by clicking its icon on the standard toolbar (fig. 4).

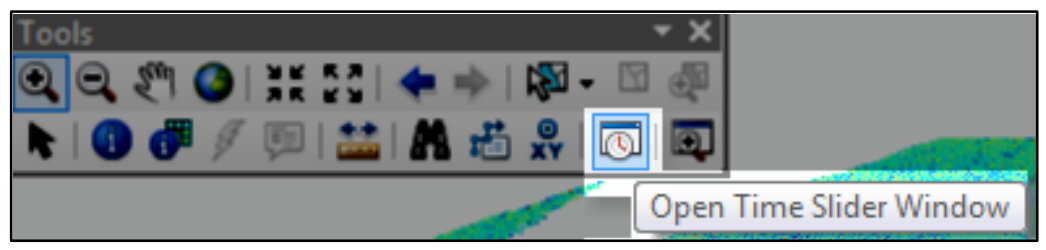

Figure 4. Opening the Time Slider toolbar.

The slider bar can now be used to cycle through the available years of data (fig. 5).

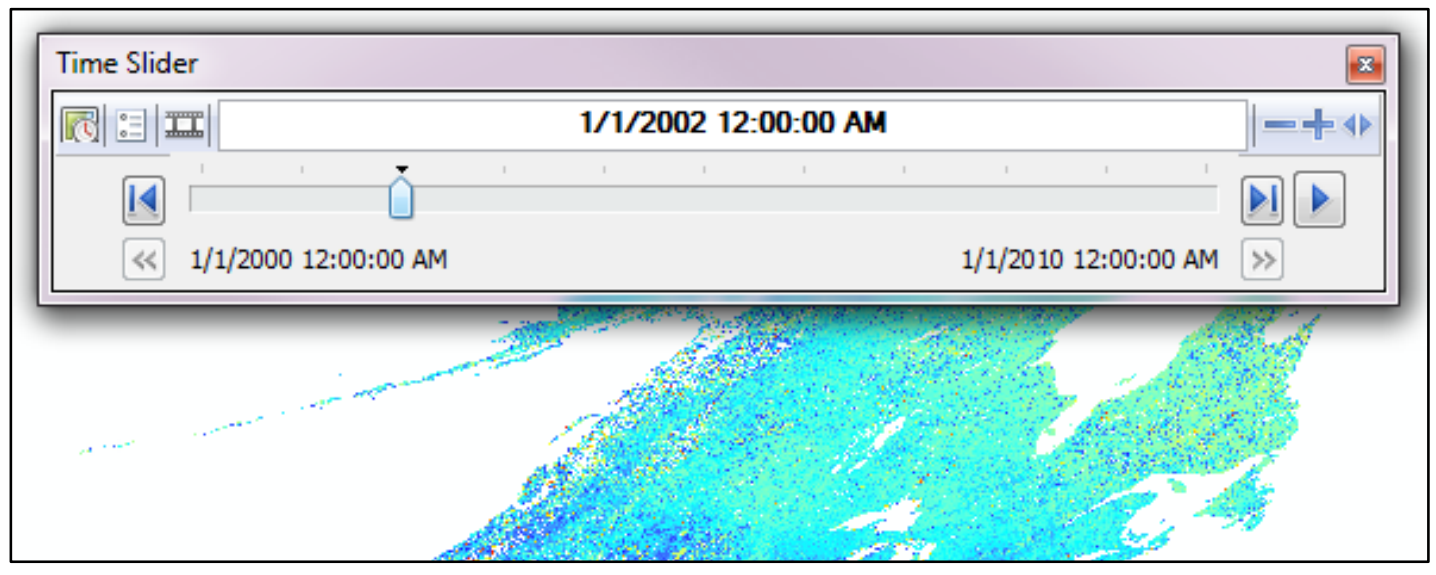

Figure 5. Cycling through multiple years' worth of data with the Time Slider toolbar.

\section{Using the "Download Local Files" Tool}

In cases where local copies of the data are needed, the "Download Local Files" tool can be used to select and save local copies of multiple years and metrics in one go. This functionality is useful when using the data with analytical tools outside of the ESRI suite, such as R or 
Maxent. The tool is straightforward to use; the user simply selects the vegetation index, years of interest, season, metrics, output file format, and a directory for saving the outputs. The extent of the data downloaded is specified by a selected spatial layer; when blank, the extent will be the current display extent. The projection of the current display or extent layer specified must be in WGS 84 Sinusoidal, the native projection of our data. To change the projection, the user can right-click the current data frame in the table of contents and select "Properties," then on the "Coordinate System" tab choose the "Predefined/Projected Coordinate Systems/World/Sinusoidal" option. Alternatively, adding one of our phenology layers to the display of a blank map will set the projection automatically.

\section{Using the "Summarize Phenology Data for Polygons" Tool}

The "Summarize Phenology data for polygons" tool extracts and averages various metrics from the phenology image services and uses R software to produce a series of charts from the extracted data. The user supplies a polygon or series of polygons as a shape file or geodatabase feature class. Because the structure of polygon vector datasets can vary, the user must also specify the string field that contains the values used to designate the unique values to summarize within. For example, a user might have a shape file with dozens of polygons. Six of these polygons make up a single management unit and have the same name in the "legal_name" field. The rest make up a second management unit and share a different name in the "legal_name" field. By selecting "legal_name" as the field, the data will be aggregated appropriately.

All outputs are saved to the output folder and include a CSV file with all of the extracted values. This file can be used for subsequent analysis in external applications if needed.

\section{Notes for Using This Toolset and the Image Services}

Because the data are delivered over the Internet, speed and bandwidth limitations should be considered. Running large geoprocessing and downloading operations might best be done overnight when competition for resources is limited. Care should also be exercised in specifying a manageable processing extent in the environmental settings as the data volume is being transmitted over the Internet. Processing extents on the county scale or even larger should work well, although analysis of phenology across such a large spatial extent arguably has few applications.

The use of these data in scripted applications using ArcPy is supported. The code of the Python scripts distributed in the scripts folder of this toolbox can provide examples of how to do this.

\section{For More Information on ESRI Image Services}

- ESRI-ArcGIS Server Image Services and Image Extension http://www.esri.com/library/fliers/pdfs/arcgis-server-image-services.pdf

- ArcGIS Resources-About adding an image service layer to ArcMap http://resources.arcgis.com/en/help/main/10.1/index.html\#//00sp0000000m000000 